\title{
Ignition in the Viscous Layer Between Counterflowing Streams: Asymptotic Theory with Comparison to Experiments
}

\author{
R. SEISER, K. SESHADRI,* and E. PISKERNIK \\ Center for Energy and Combustion Research, Department of Mechanical and Aerospace Engineering, \\ University of California at San Diego, La Jolla, CA 92093-0411, USA \\ A. LIÑÁN \\ Departamento de Motopropulsión y Termofuidodinámica, Universidad Politécnica de Madrid, \\ 28040 Madrid, Spain
}

\begin{abstract}
A formulation is given for describing ignition in nonpremixed systems. Steady laminar flow of two counterflowing streams toward a stagnation plane is considered. One stream comprises fuel and the other oxygen. The characteristic Reynolds numbers of the counterflowing streams are presumed to be large so that the thickness of the viscous layer formed in the vicinity of the stagnation plane is small. The chemical reaction between fuel and oxygen that takes place in the viscous layer is described by a one-step overall process. The activation energy of the reaction is presumed to be large in comparison to the thermal energy. The asymptotic theory developed here makes available explicit formulae for predicting ignition in the viscous layer. From these results a simple but reasonably accurate method is developed for deducing the activation energy, $E$, and frequency factor, $B$, of the rate of the one-step reaction between the fuel and oxygen. To illustrate the application of this method, experiments are carried out in the counterflow configuration. The fuels tested are $n$-heptane, $n$-decane, JP-10, and toluene. Experimental data obtained are the velocities and temperatures of counterflowing streams at ignition. Values of $E$ and $B$ are obtained by using the experimental data in the formulae given by the asymptotic theory. These values of $E$ and $B$ are found to agree well with those obtained from numerical calculations.
\end{abstract}

\section{INTRODUCTION}

Ignition of hydrocarbon fuels plays a critical role in the performance of practical combustion systems. One example is ignition of fuel sprays in diesel engines, another is ignition of end gases in spark ignition engines. Here, an activation energy asymptotic theory is developed for describing ignition in nonpremixed systems. The results of the theory are used to interpret experiments on ignition conducted in the counterflow configuration. Analyses of this kind help to elucidate the influence of various parameters on ignition.

In a previous study, Liñán and Williams [1] presented a general formulation for describing ignition in unsteady mixing layers established between two streams, one comprising fuel and the other oxygen. This analysis was performed using one-step chemistry with nonunity values of Lewis numbers for the reactants. Steady flows and flows where the strain and pressure change with time were considered. For steady flows, where changes in density in the mixing layer are small, the reduced Damköhler number at ignition was given as a function of the Lewis number of the fuel. Here, the analysis of Liñán and Williams [1] is extended to steady flows where the changes in density in the mixing layer are not small.

Other theoretical studies of ignition in steady $[2-4]$ and unsteady $[5,6]$ nonpremixed systems have previously been carried out using one-step chemistry and employing the approximation that the Lewis numbers of the reactants are equal to unity. The analysis of Liñan [3] is noteworthy. It postulated four different structures for the mixing layer established between the reactant streams. These different structures were called regimes. One of these regimes, called the ignition regime, was used in previous studies to analyze ignition in nonpremixed systems $[1,3,4]$. This regime is used in the present analysis.

In practical systems, such as those encountered in nonpremixed combustion of diesel, the 
temperature and density of the fuel stream will be different from those of the oxidizer stream. Also the Lewis numbers of the fuel will be different from unity. Previous analyses, cited above, either invoke the approximation that the Lewis numbers of reactants are equal to unity or neglect changes of density in the mixing layer. This is one of the reasons for developing the present analysis. Another reason is to establish a theoretical framework for interpreting experiments on ignition in nonuniform flows. The counterflow configuration has been used in numerous experimental studies to elucidate the physical and chemical mechanisms of extinction [7-11] and ignition [12-14]. A previous asymptotic analysis gave a method for interpreting experimental data on extinction of nonpremixed flames [15]. This previous analysis has been used to deduce overall activation energies and frequency factors of one-step reactions of a number of fuels with oxygen using experimental extinction data $[7,8]$. The present theory gives a procedure for analyzing ignition experiments performed in the counterflow configuration.

The asymptotic analysis is developed in the section, "Asymptotic Analysis," and experiments on ignition are described in the subsequent section. Overall activation energies and frequency factors deduced from the experimental data, using the formulae derived in the asymptotic analysis are given in "Overall Chemical-Kinetic Rate Parameters."

\section{ASYMPTOTIC ANALYSIS}

\section{Formulation}

Steady, axisymmetric, laminar flow of two counterflowing streams toward a stagnation plane is considered here. A schematic illustration of the counterflow configuration is shown in Fig. 1. The cylindrical coordinate system is used with $r$ denoting the radial coordinate and $z$ the axial coordinate. The stagnation plane is presumed to be located at $z=z_{\mathrm{s}}$. The oxidizer stream is presumed to flow toward the stagnation plane from the region where $z>z_{\mathrm{s}}$ while the fuel stream flows toward the stagnation plane from the region where $z<z_{s}$. The characteristic Reynolds numbers of the counterflowing

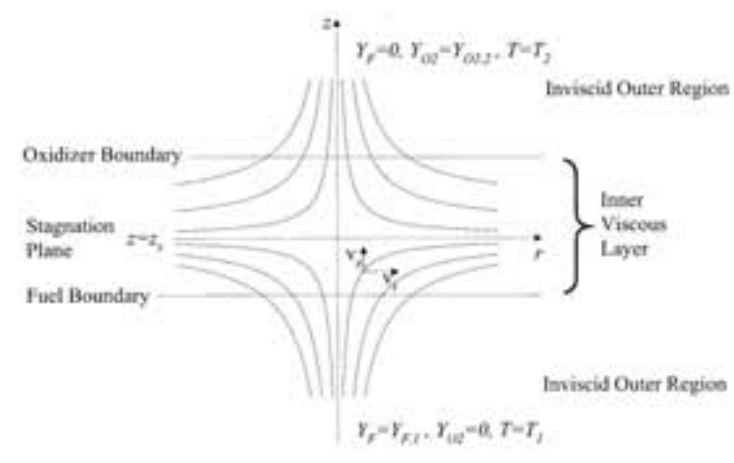

Fig. 1. Schematic illustration of the counterflow configuration.

streams are presumed to be large so that the thickness of the viscous layer around $z_{s}$, where mixing and reaction take place, is small [16]. Outside the viscous layer the flow is presumed to be nonreactive and inviscid, and the spatial gradients of temperature and mass fraction of species are presumed to be small. The boundary between the outer inviscid region of the oxidizer stream and the inner viscous boundary-layer is called the oxidizer-boundary, and the boundary between the outer inviscid region of the fuel stream and the inner viscous boundary-layer is called the fuel-boundary.

In the viscous layer changes in pressure, $p$, in the radial direction from the stagnation point, $\partial p / \partial r$, is given by [16]

$-\partial p / \partial r=r \rho_{2} a_{2}^{2} / 4=r \rho_{1} a_{1}^{2} / 4$

where $\rho$ denotes the density and subscripts 2 and 1 denote conditions at the oxidizer-boundary and the fuel-boundary respectively. The quantities $a_{2}$ and $a_{1}$ are the characteristic strain rates at these boundaries. If the flow outside the viscous layer is irrotational then the strain rates are constant in the outer inviscid region. If the outer flow is rotational (plug flow) then the strain rates in the inviscid region depend on $z$ [16]. For rotational outer flow, the strain rates in $\mathrm{Eq} .1$ are those evaluated at the stagnation plane with equations describing the structure of the outer flows [16]. The results of the analysis developed here can be applied to rotational as well as irrotational outer flow as long as the appropriate strain rate is used in Eq. 1.

The chemical reaction taking place in the viscous layer is represented by the one-step, irreversible process 
$\nu_{\mathrm{F}}$ Fuel $+\nu_{\mathrm{O}_{2}}$ Oxygen $\rightarrow$ Products

where $\nu_{\mathrm{F}}$ and $\nu_{\mathrm{O}_{2}}$ are the stoichiometric coefficients. The reaction rate, $w$, is given by

$w=\rho^{2}\left[Y_{\mathrm{F}} Y_{\mathrm{O}_{2}} /\left(W_{\mathrm{F}} W_{\mathrm{O}_{2}}\right)\right] B \exp \left[-E /\left(R^{0} T\right)\right]$

where $Y_{\mathrm{F}}$ and $Y_{\mathrm{O}_{2}}$ represent the mass fractions of fuel and oxygen respectively, and $W_{\mathrm{F}}$ and $W_{\mathrm{O}_{2}}$ their molecular weights. The temperature is denoted by $T$ and the universal gas constant by $R^{0}$. The activation energy $E$ and the frequency factor $B$ are the overall chemical-kinetic rate parameters. In the viscous layer all quantities except the radial component of the flow velocity depend only on $z$ [16]. The dimensional equations describing the structure of the viscous layer are:

Conservation of mass,

$\frac{1}{r} \frac{\partial}{\partial r}\left(\rho r v_{\mathrm{r}}\right)+\frac{d}{d z}\left(\rho v_{\mathrm{z}}\right)=0$.

Radial component of the equation of motion,

$\rho v_{\mathrm{r}} \frac{\partial v_{\mathrm{r}}}{\partial r}+\rho v_{\mathrm{z}} \frac{\partial v_{\mathrm{r}}}{\partial z}=\frac{r \rho_{2} a_{2}^{2}}{4}+\frac{\partial}{\partial z}\left(\mu \frac{\partial v_{\mathrm{r}}}{\partial z}\right)$.

Balance equation for mass fraction of fuel, $Y_{\mathrm{F}}$

$\rho v_{\mathrm{z}} \frac{d Y_{\mathrm{F}}}{d z}=\frac{d}{d z}\left(\rho D_{\mathrm{F}} \frac{d Y_{\mathrm{F}}}{d z}\right)-\nu_{\mathrm{F}} W_{\mathrm{F}} w$

Balance equation for mass fraction of oxygen, $Y_{\mathrm{O}_{2}}$,

$\rho v_{\mathrm{z}} \frac{d Y_{\mathrm{O}_{2}}}{d z}=\frac{d}{d z}\left(\rho D_{\mathrm{O}_{2}} \frac{d Y_{\mathrm{O}_{2}}}{d z}\right)-\nu_{\mathrm{O}_{2}} W_{\mathrm{O}_{2}} w$.

Energy equation for the temperature, $T$,

$\rho c_{\mathrm{p}} v_{\mathrm{z}} \frac{d T}{d z}=\frac{d}{d z}\left(\lambda \frac{d T}{d z}\right)+\nu_{\mathrm{F}} W_{\mathrm{F}} q_{\mathrm{F}} w$.

Here $v_{\mathrm{r}}$ and $v_{\mathrm{z}}$ respectively denote the radial and axial components of the flow velocity. The viscosity is denoted by $\mu$, the diffusion coefficient of fuel by $D_{\mathrm{F}}$, the diffusion coefficient of oxygen by $D_{\mathrm{O}_{2}}$, the heat capacity by $c_{\mathrm{p}}$, and the thermal conductivity by $\lambda$. The pressure, density, and temperature are presumed to be related by the ideal gas equation of state $p=$ $\rho R^{0} T / \hat{W}$, where the average molecular weight $\hat{W}$ is presumed to be constant.

Boundary conditions for Eqs. 3, 4, 5, 6, and 7 are applied at the edges of the mixing layer. At the oxidizer-boundary in the region where $z>$ $z_{\mathrm{s}}, v_{\mathrm{r}}=a_{2} r / 2, Y_{\mathrm{F}}=0, Y_{\mathrm{O}_{2}}=Y_{\mathrm{O}_{2}, 2}$, and $T=$ $T_{2}$. At the fuel-boundary in the region where $z<z_{\mathrm{s}}, v_{\mathrm{r}}=a_{1} r / 2, Y_{\mathrm{F}}=Y_{\mathrm{F}, 1}, Y_{\mathrm{O}_{2}}=0$, and $T=$ $T_{1}$.

The describing equations are nondimensionalized by introducing the following definitions:

$$
\begin{gathered}
\eta=\int_{z_{\mathrm{s}}}^{z} \frac{\rho}{\rho_{2}}\left(\frac{\rho_{2} a_{2} c_{\mathrm{p}}}{\lambda_{2}}\right)^{0.5} d z ; \quad v_{\mathrm{r}}=r \frac{a_{2}}{2} \frac{d f}{d \eta} ; \\
v_{\mathrm{z}}=-\frac{\rho_{2}}{\rho}\left(\frac{a_{2} \lambda_{2}}{\rho_{2} c_{\mathrm{p}}}\right)^{0.5} f ; \\
y_{\mathrm{F}}=\frac{Y_{\mathrm{F}}}{Y_{\mathrm{F}, 1}} ; \quad y_{\mathrm{O}_{2}}=\frac{Y_{\mathrm{O}_{2}}}{\nu Y_{\mathrm{F}, 1}} ; \quad \theta=\frac{T_{2}-T}{T_{2}-T_{1}} ; \quad(8) \\
\nu=\frac{\nu_{\mathrm{O}_{2}} W_{\mathrm{O}_{2}}}{\nu_{\mathrm{F}} W_{\mathrm{F}}} ; \quad \gamma=\frac{T_{2}-T_{1}}{T_{2}} ; \quad q=\frac{Y_{\mathrm{F}, 1} q_{\mathrm{F}}}{c_{\mathrm{p}}\left(T_{2}-T_{1}\right)} .
\end{gathered}
$$

Here $\eta$ is the independent variable, $f$ the stream function, $\theta$ the nondimensional temperature, $y_{\mathrm{F}}$ and $y_{\mathrm{O}_{2}}$ are normalized mass fractions of fuel and oxygen respectively. The quantity $q_{\mathrm{F}}$ is the heat release per unit mass of fuel consumed.

In the analysis the heat capacity $c_{\mathrm{p}}$, the product $\rho \mu$, Prandtl number $\operatorname{Pr}=\mu c_{\mathrm{p}} / \lambda$, and the Lewis numbers $L_{\mathrm{F}}=\lambda /\left(\rho c_{\mathrm{p}} D_{\mathrm{F}}\right)$ and $L_{\mathrm{O}_{2}}=$ $\lambda /\left(\rho c_{\mathrm{p}} D_{\mathrm{O}_{2}}\right)$ are presumed to be constants. Constant $\operatorname{Pr}$ leads to the result $\rho \lambda$ is constant. Constant $L_{\mathrm{F}}$ and $L_{\mathrm{O}_{2}}$ leads to the result $\rho^{2} D_{\mathrm{F}}$ and $\rho^{2} D_{\mathrm{O}}$ are constants.

Using Eq. 8, Eq. 4 can be written as

$$
2 \operatorname{Pr} \frac{d^{3} f}{d \eta^{3}}+2 f \frac{d^{2} f}{d \eta^{2}}-\left(\frac{d f}{d \eta}\right)^{2}+1-\gamma \theta=0 .
$$

Using Eq. 8, Eqs. 5, 6, and 7 can be written as

$$
\begin{aligned}
& \frac{1}{L_{\mathrm{F}}} \frac{d^{2} y_{\mathrm{F}}}{d \eta^{2}}+f \frac{d y_{\mathrm{F}}}{d \eta}=\frac{1}{L_{\mathrm{O}_{2}}} \frac{d^{2} y_{\mathrm{O}_{2}}}{d \eta^{2}}+f \frac{d y_{\mathrm{O}_{2}}}{d \eta} \\
& =\frac{1}{q} \frac{d^{2} \theta}{d \eta^{2}}+\frac{f}{q} \frac{d \theta}{d \eta} \\
& =\frac{\nu_{\mathrm{O}_{2}} Y_{\mathrm{F}, 1} \rho B}{W_{\mathrm{F}} a_{2}} y_{\mathrm{F}} y_{\mathrm{O}_{2}} \exp \left(-\frac{E}{R^{0} T}\right) .
\end{aligned}
$$


In the constant density analysis of Liñán and Williams [1], $\gamma=0$ and $f=\eta$. Here $\gamma$ is presumed to be of the order of unity. Boundary conditions for Eqs. 9, and 10 are

For $\eta \rightarrow \infty$

$$
\begin{array}{rlrl}
d f / d \eta & =1, \quad y_{\mathrm{F}}=0, & y_{\mathrm{O}_{2}} \\
& =Y_{\mathrm{O}_{2}, 2} /\left(\nu Y_{\mathrm{F}, 1}\right), & & \theta=0 .
\end{array}
$$

For $\eta \rightarrow-\infty$

$$
\begin{aligned}
d f / d \eta & =(1-\gamma)^{0.5}, \quad y_{\mathrm{F}}=1, \quad y_{\mathrm{O}_{2}} \\
& =0, \quad \theta=1 .
\end{aligned}
$$

Equation 9 is coupled to the equation for $\theta$ in Eq. 10. These equations, however, are uncoupled from the equations for $y_{\mathrm{F}}$ and $y_{\mathrm{O}}$, shown in Eq. 10. The asymptotic analysis is performed for $T_{2}>T_{1}$ and large values of the Zel'dovich number, $\beta$, given by

$\beta=\frac{E\left(T_{2}-T_{1}\right)}{R^{0} T_{2}^{2}}$.

In the analysis of Liñan [3] ignition was presumed to take place in the "ignition-regime." In this regime the chemical reaction is frozen in the first approximation. Following this analysis, the nonreactive structure of the viscous layer is obtained in the following section. Perturbation analysis is then carried out to obtain the critical conditions of ignition.

\section{Structure of the Nonreactive Viscous Layer}

In the nonreactive viscous layer the profiles of velocity, mass fraction of fuel and oxygen, and temperature can be obtained by integrating Eqs. 9 and 10 after neglecting the chemical source term in Eq. 10. The mass fraction of fuel, mass fraction of oxygen, and temperature in the nonreactive viscous layer are represented by $y_{\mathrm{F}, \mathrm{f}} y_{\mathrm{O}, \mathrm{f}}$, and $\theta_{\mathrm{r}}$ respectively. These quantities are given by

$$
\begin{aligned}
\frac{1}{L_{\mathrm{F}}} \frac{d^{2} y_{\mathrm{F}, \mathrm{S}}}{d \eta^{2}}+f \frac{d y_{\mathrm{F}, \mathrm{f}}}{d \eta} & =\frac{1}{L_{\mathrm{O}_{2}}} \frac{d^{2} y_{\mathrm{O}_{2}, \mathrm{f}}}{d \eta^{2}}+f \frac{d y_{\mathrm{O}_{2}, \mathrm{f}}}{d \eta} \\
& =\frac{1}{q} \frac{d^{2} \theta_{\mathrm{f}}}{d \eta^{2}}+\frac{f}{q} \frac{d \theta_{\mathrm{f}}}{d \eta}=0 .
\end{aligned}
$$

The asymptotic analysis requires values of $y_{\mathrm{F}, \mathrm{f}}$, $y_{\mathrm{O}, \mathrm{f}}$, and $\theta_{\mathrm{f}}$ close to the oxidizer-boundary, where $\eta$ is large. The leading order value of $f$ in the limit of large $\eta$ is $f=\left(\eta-B_{2}\right)$, where $B_{2}$ is an arbitrary constant of the order of unity.
The set of Eqs. 9 and 14 do not change if the value of the independent variable $\eta$ is increased or decreased by a constant. Therefore, the choice $B_{2}=0$ is made. This choice fixes the origin. Introducing this asymptotic value of $f$ into Eqs. 14 and integrating, the results

$$
\begin{aligned}
y_{\mathrm{F}, \mathrm{f}} & =\frac{F_{2}}{(2 \pi)^{0.5}\left(L_{\mathrm{F}}\right)^{0.5} \eta} \exp \left[-\frac{L_{\mathrm{F}} \eta^{2}}{2}\right], \\
y_{\mathrm{O}_{2}, \mathrm{f}} & =\frac{Y_{\mathrm{O}, 2}}{\nu Y_{\mathrm{F}, 1}}, \\
\theta_{\mathrm{f}} & =\frac{C_{2}}{(2 \pi)^{0.5} \eta} \exp \left[-\frac{\eta^{2}}{2}\right]
\end{aligned}
$$

are obtained to the leading order. $C_{2}$ and $F_{2}$ are constants of the order of unity. The asymptotic values of $y_{\mathrm{F}, \mathrm{f}}, y_{\mathrm{O}, 5}$, and $\theta_{\mathrm{f}}$ in Eq. 15 satisfy the boundary conditions given by $\mathrm{Eq} .11$. The values of $C_{2}$ and $F_{2}$ are required in the asymptotic analysis. $C_{2}$ depends on $\operatorname{Pr}$ and $\gamma$, and $F_{2}$ on $\operatorname{Pr}, \gamma$, and $L_{\mathrm{F}}$. In the constant density analysis of Linán and Williams [1], $C_{2}=F_{2}=1$. The values of $C_{2}$ and $F_{2}$ are obtained from numerical integration of Eqs. 9 and Eq. 14. The numerical integration requires an asymptotic value of $f$ for large $\eta$. This asymptotic value, deduced from Eqs. 9 and 15, is given by $f=\eta+\left(A_{2} / \eta^{2}\right) \exp \left[-\eta^{2} /(2 P r)\right]+\gamma \theta /$ [2(1-Pr) $\left.\eta^{3}\right]$, where $A_{2}$ is a constant of the order of unity. Values of $A_{2}$ are obtained from numerical integration of Eqs. 9 and 14.

The structures of the nonreactive flow-field are calculated for $\mathrm{Pr}=0.7$, for $\gamma$ between 0.5 and 0.9 and $L_{\mathrm{F}}$ between 0.7 and 3.5. Values of $A_{2}, C_{2}$, and $F_{2}$ are so chosen that Eq. 12 is satisfied. Profiles of $f, y_{\mathrm{F}, f}$ and $\theta_{\mathrm{f}}$ are obtained. Profiles of $y_{\mathrm{O}_{2}, \mathrm{f}}$ are not calculated because they are not used in the asymptotic analysis. Figure 2

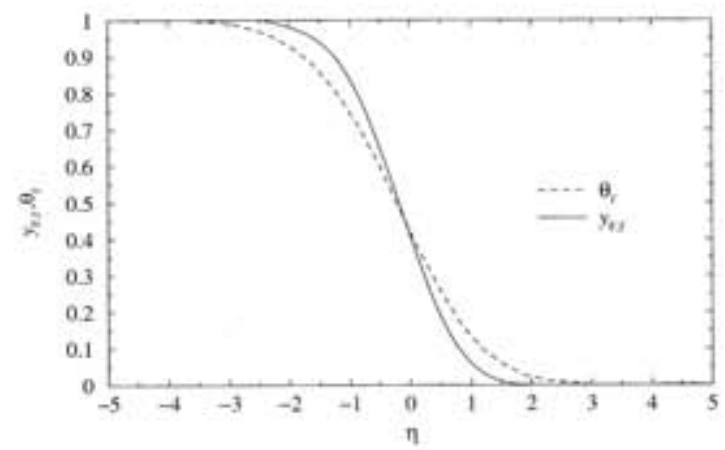

Fig. 2. Profiles of $y_{F, f}$ and $\theta_{t}$ in the nonreactive viscous layer for $\operatorname{Pr}=0.7, \gamma=0.7$, and $L_{F}=2$. 
TABLE 1

Profiles in Nonreactive Viscous Layer for $\mathrm{Pr}=0.7, \gamma=0.7$, and $L_{\mathrm{F}}=2$

\begin{tabular}{|c|c|c|c|c|c|c|c|}
\hline$\eta$ & $f$ & $\begin{array}{l}d f i \\
d \eta\end{array}$ & $d^{2} f / d \eta^{2}$ & $y_{F, f}$ & $d y_{\mathrm{F}, j} / d \eta$ & $\theta_{\mathrm{f}}$ & $d \theta_{i} / d \eta$ \\
\hline 5.000 & 5.000 & 1.000 & 0.000 & 0.000 & 0.000 & 0.000 & 0.000 \\
\hline 4,000 & 4.000 & 1,000 & 0.000 & 0.000 & 0.000 & 0.000 & 0.000 \\
\hline 3.000 & 3.000 & 1.000 & 0.001 & 0.000 & 0.000 & 0.001 & -0.004 \\
\hline 2.500 & 2.500 & 0.999 & 0.003 & 0.000 & -0.001 & 0.005 & -0.014 \\
\hline 2.000 & 2.001 & 0.996 & 0.011 & 0.002 & -0.008 & 0.019 & -0.045 \\
\hline 1.500 & 1.505 & 0.986 & 0.034 & 0.013 & -0.046 & 0.055 & -0.107 \\
\hline 1.000 & 1.018 & 0.958 & 0.078 & 0.061 & -0.162 & 0.131 & -0.201 \\
\hline 0.500 & 0.551 & 0.906 & 0.133 & 0.189 & -0.355 & 0.257 & -0.297 \\
\hline 0.000 & 0.117 & 0.828 & 0.173 & 0.407 & -0.494 & 0.421 & -0.351 \\
\hline-0.500 & -0.275 & 0.740 & 0.172 & 0.652 & -0.455 & 0.596 & -0.337 \\
\hline-1.000 & -0.624 & 0.662 & 0.136 & 0.840 & -0.289 & 0.749 & -0.268 \\
\hline-1.500 & -0.940 & 0.606 & 0.087 & 0.943 & -0.132 & 0.861 & -0.181 \\
\hline-2.000 & -1.234 & 0.573 & 0.046 & 0.984 & -0.044 & 0.932 & -0.105 \\
\hline-2.500 & -1.516 & 0.557 & 0.020 & 0.997 & -0.011 & 0.970 & -0.053 \\
\hline-3.000 & -1.793 & 0.551 & 0.008 & 0.999 & -0.002 & 0.989 & -0.023 \\
\hline-4.0000 & -2.342 & 0.548 & 0.001 & 1,000 & 0.000 & 0.999 & -0.003 \\
\hline-5.000 & -2.890 & 0.548 & 0.000 & 1.000 & 0.000 & 1.000 & 0.000 \\
\hline
\end{tabular}

shows numerically calculated profiles of $y_{\mathrm{F}, \mathrm{f}}$ and $\theta_{\mathrm{f}}$ for $\operatorname{Pr}=0.7, \gamma=0.7$, and $L_{\mathrm{F}}=2$. Figure 2 shows that $y_{\mathrm{F}, \mathrm{f}}$ increases more rapidly than $\theta_{\mathrm{f}}$ from 0 to 1 , because the Lewis number of the fuel is greater than unity. Table 1 shows the numerically calculated values of $f, d f / d \eta, d^{2} f /$ $d \eta^{2}, y_{\mathrm{F}, \mathrm{f}}, d y_{\mathrm{F}, \mathrm{f}} d \boldsymbol{d}, \theta_{\mathrm{f}}$, and $d \theta_{\mathrm{f}} / d \eta$ for $P r=0.7$, $\gamma=0.7$, and $L_{F}=2$. Figure 3 shows $C_{2}$ as a function of $\gamma$, and Fig. 4 shows $F_{2}$ as a function of $\gamma$ for various values of $L_{\mathrm{F}}$. Values of $F_{2}$ at fixed $L_{\mathrm{F}}$, and values of $C_{2}$ decrease with increasing $\gamma$. Values of $F_{2}$ at fixed $\gamma$ decrease with increasing $L_{\mathrm{F}}$.

\section{Analysis of the Reactive Viscous Layer}

The analysis given here follows that of Liñán and Williams [1]. In the "ignition regime" [3],

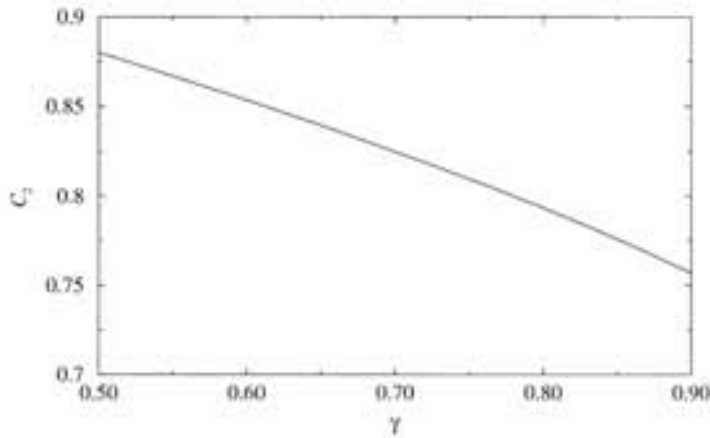

Fig. 3. Values of $C_{2}$ as a function of $\gamma$ for $\operatorname{Pr}=0.7$. the increase in temperature above that in the nonreactive viscous layer is of the order of $\beta^{-1}$. To obtain the critical conditions of ignition the expansions

$$
\begin{aligned}
\theta & =\theta_{\mathrm{f}}-\beta^{-1} \varphi+\cdots \\
y_{\mathrm{F}} & =y_{\mathrm{F}, \mathrm{f}}-q^{-1} \beta^{-1} \alpha_{\mathrm{F}}+\cdots \\
y_{\mathrm{O}_{2}} & =y_{\mathrm{O}_{2}, \mathrm{f}}-q^{-1} \beta^{-1} \alpha_{\mathrm{O}_{2}}+\cdots,
\end{aligned}
$$

are introduced where $\varphi, \alpha_{\mathrm{F}}$, and $\alpha_{\mathrm{O}_{2}}$ are presumed to be of the order of unity. Using the definition of $\theta$ given in Eq. 8 and the expansion in Eq. 16 the temperature distribution $T=$ $T_{2}-\left(T_{2}-T_{1}\right) \theta_{\mathrm{f}}+\beta^{-1}\left(T_{2}-T_{1}\right) \varphi$ is obtained. Introducing this expansion for $T$, and those given in Eq. 16 into Eq. 10, the equations

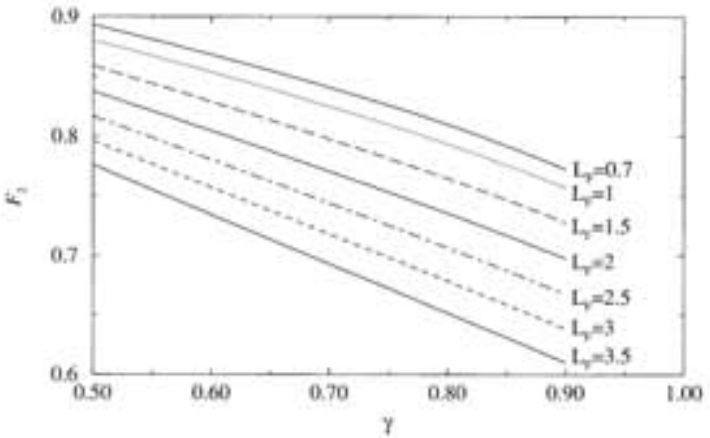

Fig. 4. Values of $F_{2}$ as a function of $\gamma$ for $\operatorname{Pr}=0.7$ and various values of $L_{\mathrm{P}}$. 


$$
\begin{aligned}
-\frac{1}{L_{\mathrm{F}}} \frac{d^{2} \alpha_{\mathrm{F}}}{d \eta^{2}}-f \frac{d \alpha_{\mathrm{F}}}{d \eta} & =-\frac{1}{L_{\mathrm{O}_{2}}} \frac{d^{2} \alpha_{\mathrm{O}_{2}}}{d \eta^{2}}-f \frac{d \alpha_{\mathrm{O}_{2}}}{d \eta}=-\frac{d^{2} \varphi}{d \eta^{2}}-f \frac{d \varphi}{d \eta} \\
& =\frac{\nu_{\mathrm{O}_{2}} Y_{\mathrm{F}, 1} q \beta \rho B}{W_{\mathrm{F}} a_{2}} \exp \left(-\frac{E}{R^{0} T_{2}}\right)\left(y_{\mathrm{F}, \mathrm{f}} y_{\mathrm{O}_{2}, \mathrm{f}}\right) \exp \left(\varphi-\beta \theta_{\mathrm{f}}\right),
\end{aligned}
$$

are obtained. For large $\beta$, chemical reaction will be negligibly small except where $\beta \theta_{\mathrm{f}}$ is of the order of unity. Ignition would take place close to the oxidizer-boundary because the value of $\theta_{\mathrm{f}}$ is small near this boundary. Following the analysis in Ref. 1, chemical reaction is presumed to take place in a region around $\eta_{\mathrm{r}}$, where $\beta \theta_{\mathrm{f}}=1$. Using Eq. 15, $\eta_{\mathrm{r}}$ is given by

$\frac{\beta C_{2}}{(2 \pi)^{0.5} \eta_{\mathrm{r}}} \exp \left(-\frac{\eta_{\mathrm{r}}^{2}}{2}\right)=1$.

The value of $\eta_{\mathrm{r}}$ is expected to be large. To analyze the structure of the reaction layer, it is convenient to introduce the independent variable $\zeta$, given by the equation

$\zeta=\eta-\eta_{\mathrm{r}}$

Using Eqs. 15 and 18, a quantity $\xi=\beta \theta_{\mathrm{f}}$ is defined by the following equation:

$\xi=\beta \theta_{\mathrm{f}}=\exp \left(-\zeta \eta_{\mathrm{r}}\right)$,

where the approximation $\eta^{2} \simeq \eta_{\mathrm{r}}^{2}+2 \zeta \eta_{\mathrm{r}}$ is employed. Using Eqs. 15, 18, 19, and 20, $y_{\mathrm{F}, \mathrm{f}}$ is given by [1]

$y_{\mathrm{F}, \mathrm{f}}=F_{2}\left(C_{2} \beta\right)^{-L_{\mathrm{F}}}\left(\eta_{\mathrm{r}} \sqrt{2 \pi}\right)^{L_{\mathrm{F}}-1} L_{\mathrm{F}}^{-0.5} \xi^{L_{\mathrm{F}}}$.

Introducing the asymptotic value $f=\eta$ for large $\eta$, and Eqs. 15, 19, 20, and 21 into Eq. 17 the differential equation

$\frac{d^{2} \varphi}{d \zeta^{2}}+\eta_{\mathrm{r}} \frac{d \varphi}{d \zeta}+D_{\mathrm{m}} \xi^{L_{\mathrm{F}}} \exp (\varphi-\xi)=0$

is obtained [1]. Here the Damköhler number, $D_{\mathrm{m}}$ is given by

$$
\begin{aligned}
& D_{\mathrm{m}}=\frac{F_{2} \nu_{\mathrm{F}} Y_{\mathrm{O}_{2}, 2} q \rho_{2} B}{C_{2}^{L_{\mathrm{F}}} W_{\mathrm{O}_{2}} a_{2} L_{\mathrm{F}}^{0.5}}\left(\frac{\eta_{\mathrm{r}} \sqrt{2 \pi}}{\beta}\right)^{L_{\mathrm{F}}-1} \\
& \cdot \exp \left(-\frac{E}{R^{0} T_{2}}\right) .
\end{aligned}
$$

Boundary conditions to Eq. 22 are $\varphi \rightarrow \varphi_{\mathrm{m}}$ for $\zeta \rightarrow-\infty$, and $\varphi \rightarrow 0$ for $\zeta \rightarrow \infty$, where $\varphi_{\mathrm{m}}$ is an eigenvalue to be determined by matching with the solution in the reaction layer [1]. Using Eq. 20, Eq. 22 can be written as [1]

$\frac{d^{2} \varphi}{d \xi^{2}}+\Delta \xi^{L_{\mathrm{F}}-2} \exp (\varphi-\xi)=0$,

where the modified Damköhler number $\Delta$ is given by

$\Delta=D_{\mathrm{m}} \eta_{\mathrm{r}}^{-2}$.

Boundary conditions to Eq. 24 are $\varphi \rightarrow \varphi_{\mathrm{m}}$ for $\xi \rightarrow \infty$, and $\varphi \rightarrow 0$ for $\xi \rightarrow 0$.

Equation 24 is identical to Eq. A22 in Liñán and Williams [1]. The value of $\Delta$ at ignition denoted by $\Delta_{\mathrm{I}}$ is plotted in Fig. 2 of Ref. 1 as a function of $L_{\mathrm{F}}$. For $L_{\mathrm{F}}=2, \Delta_{\mathrm{I}}=0.5$. The results of the asymptotic analysis are used to analyze experimental data on ignition obtained in the counterflow configuration.

\section{EXPERIMENTS ON IGNITION}

\section{Apparatus and Procedure}

The asymptotic analysis developed in the previous section is used to deduce overall chemicalkinetic rate parameters from experimental data on ignition of various fuels. The fuels tested are $n$-heptane $\left(n-\mathrm{C}_{7} \mathrm{H}_{16}\right)$, n-decane $\left(n-\mathrm{C}_{10} \mathrm{H}_{22}\right)$, JP-10 $\left(\mathrm{C}_{10} \mathrm{H}_{16}\right)$, and toluene $\left(\mathrm{C}_{7} \mathrm{H}_{8}\right)$. JP-10 is included in the present study because it is considered for use in pulse-detonation engines [17]. Figure 5 shows a schematic illustration of the counterflow burner. The burner is made up of two parts: the bottom part comprises the fuel duct and the exhaust system, while the top part comprises the oxidizer duct and heating elements. A jet of prevaporized liquid fuel mixed with nitrogen is introduced from the bottom part and a jet of heated air from the top part. The bottom part is made of aluminum. The inner diameter of the fuel duct is $23 \mathrm{~mm}$. Near the exit of the fuel duct several fine wire screens 


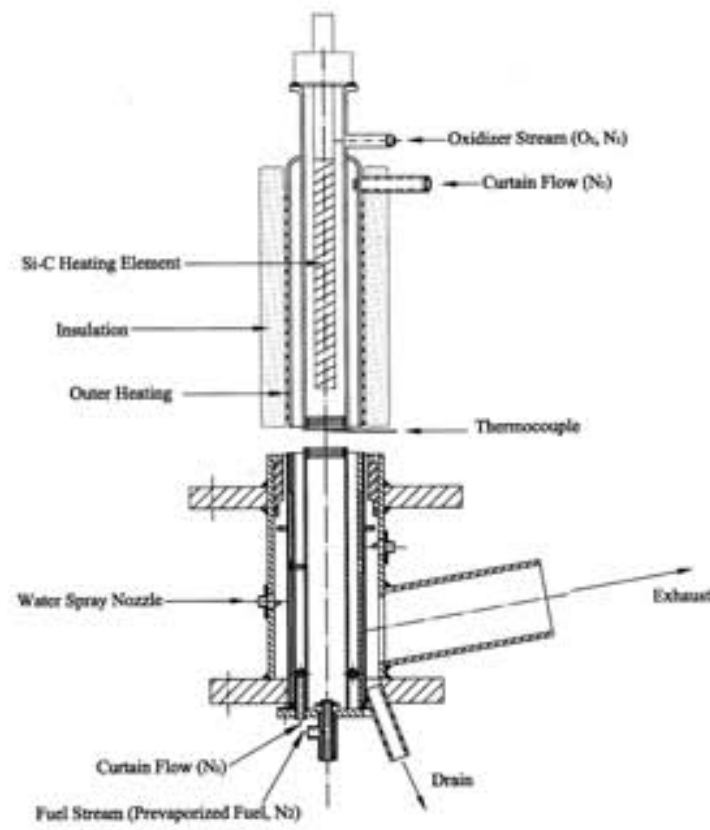

Fig. 5. Schematic illustration of the apparatus.

(200 mesh) are placed to make the velocity profile uniform. From an annular region that surrounds the fuel duct, a "curtain" flow of nitrogen flows parallel to the fuel stream. The region that surrounds this "curtain" nitrogen flow is connected to an exhaust system. The hot gases from the mixing layer, between the ducts, are cooled in this region by water sprays before they enter the exhaust system. The apparatus used for vaporizing liquid fuel, called vaporizer, is described elsewhere [11]. The vaporizer is capable of delivering a steady flow of prevaporized liquid fuel and nitrogen. The temperature of the liquid fuel in the vaporizer is maintained at a constant value. The flow lines from the vaporizer to the fuel duct are heated to prevent condensation of prevaporized fuel. The temperature of the fuel stream at the exit of the fuel duct, $T_{1}$, is measured using a thermocouple. The top part of the burner comprising the oxidizer duct is made of quartz. The inner diameter of the oxidizer duct is $23.5 \mathrm{~mm}$. Near the exit of the oxidizer duct several nichrome wire screens (100 mesh) are placed to make the velocity profile uniform. From an annular region that surrounds the oxidizer duct a "curtain" flow of nitrogen flows parallel to the oxidizer stream. The air flowing inside the oxi- dizer duct is heated by a silicon carbide heating element placed inside the oxidizer duct. Additional heating is provided by Kanthal $\mathrm{A} 1$ heating wires wound around the quartz duct. To minimize heat losses, an Alumina ceramic blanket is wrapped around the top part of the burner. The distance, $L$, between the exit of the oxidizer duct and the exit of the fuel duct, is 12 mm. Further details of the burner are given elsewhere [18].

All gaseous flowrates are measured by computer-regulated mass flow controllers. The calibrated accuracy of these mass flow controllers is $\pm 1 \%$. The temperature of the air at the exit of the burner is measured using a $\mathrm{Pt}-\mathrm{Pt} 13 \% \mathrm{Rh}$ thermocouple with wire diameter of $0.07 \mathrm{~mm}$ and a junction diameter of $0.21 \mathrm{~mm}$. The measured temperatures are corrected for radiative heat losses assuming spherical shape of the junction, a constant Nusselt number of 2.0 , and a constant emissivity of 0.2 [19]. The accuracy of the corrected temperature is expected to be better than $\pm 25 \mathrm{~K}$. The velocities of the reactants at the exits of the ducts are presumed to be equal to the ratio of their volumetric flowrates to the cross-section areas of the ducts. In the experiments the momenta of the counterflowing reactant streams $\rho_{i} V_{i}^{2}, i=1,2$ at the duct exits are kept the same. Here $V_{1}$ and $V_{2}$ are the velocities at the exit of the fuel duct and at the exit of the oxidizer duct respectively. Keeping the momenta equal ensures that the stagnation plane formed by the two streams is approximately in the middle of the region between the two duct exits. The strain rate on the oxidizer side of the stagnation plane $a_{2}$ is calculated from the equation [16]

$a_{2}=\frac{2\left|V_{2}\right|}{L}\left(1+\frac{\left|V_{1}\right| \sqrt{\rho_{1}}}{\left|V_{2}\right| \sqrt{\rho_{2}}}\right)$.

At ignition the strain rate is denoted by $a_{2,1}$ and the temperature of the oxidizer stream by $T_{2,1}$.

\section{Experimental Results}

Experiments are carried out at a pressure of 1.013 bar. In all experiments the mole fraction of prevaporized fuel, $X_{\mathrm{F}, 1}$, in the fuel stream is maintained at 0.15 . The temperatures of the fuel stream at the exit of the duct, $T_{1}$, are $378 \mathrm{~K}$, 


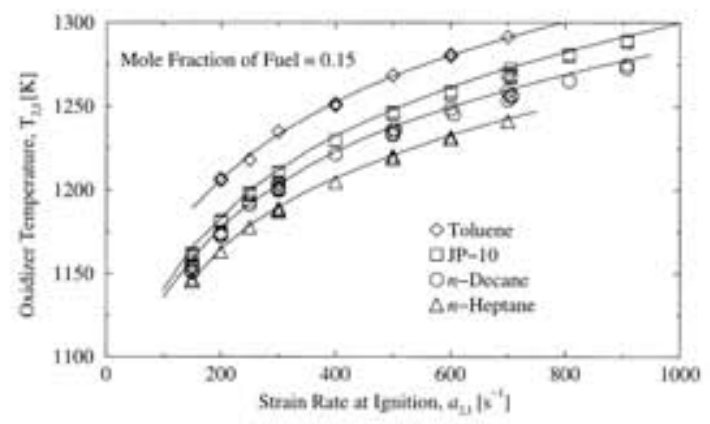

Fig. 6. Experimental data showing the oxidizer temperature, $T_{2,1}$, as a function of the strain rate, $a_{2,1}$, at ignition. The points represent measurements and the lines are results of numerical calculations obtained using one-step chemistry. The temperatures of the fuel stream are $378 \mathrm{~K}, 408 \mathrm{~K}$. $408 \mathrm{~K}$, and $378 \mathrm{~K}$ for $n$-heptane, $n$-decane, JP-10, and toluene respectively.

$408 \mathrm{~K}, 408 \mathrm{~K}$, and $378 \mathrm{~K}$ for $n$-heptane, $n$ decane, JP-10, and toluene respectively. In all experiments the oxidizer stream is air with a mass fraction of oxygen $Y_{\mathrm{O}, 2}=0.233$. At a given strain rate and oxidizer stream temperature $T_{2}<T_{2,1}$ the flow field is established. At fixed strain rate, the oxidizer temperature is gradually increased until ignition takes place. The critical values $T_{2,1}$ and $a_{2,1}$ are recorded. Figure 6 shows experimental data on ignition of $n$-heptane, $n$-decane, JP-10, and toluene, giving $T_{2,1}$ as a function of $a_{2,1}$. The points in Fig. 6 represent measurements. The lines are results of numerical calculations performed using onestep chemistry with overall chemical-kinetic rate parameters so chosen that they fit experimental data. The procedure employed to obtain the numerical results is described later. For a given fuel and strain rate, ignition will take place if the temperature of the oxidizer stream is greater than $T_{2,1}$. Figure 6 shows that for a given fuel, with increasing strain rate the value of $T_{2,1}$ increases. At a given value of the strain rate, the temperature of the oxidizer stream at ignition, $T_{2, \mathrm{I}}$, for toluene is the highest followed by JP-10, $n$-decane, and $n$-heptane. This indicates that among the fuels tested here, toluene is the most difficult to ignite followed by JP-10, $n$-decane, and $n$-heptane. Overall chemicalkinetic rate parameters are deduced using the experimental data in Fig. 6.

\section{OVERALL CHEMICAL-KINETIC RATE PARAMETERS}

The chemical reaction between the fuels $n$ heptane, $n$-decane, JP-10 and toluene, and oxygen is represented by the following one-step, irreversible process

$$
\begin{aligned}
& n-\mathrm{C}_{7} \mathrm{H}_{16}+11 \mathrm{O}_{2} \rightarrow 7 \mathrm{CO}_{2}+8 \mathrm{H}_{2} \mathrm{O}, \\
& n-\mathrm{C}_{10} \mathrm{H}_{22}+15.5 \mathrm{O}_{2} \rightarrow 10 \mathrm{CO}_{2}+11 \mathrm{H}_{2} \mathrm{O}, \\
& \mathrm{C}_{10} \mathrm{H}_{16}+14 \mathrm{O}_{2} \rightarrow 10 \mathrm{CO}_{2}+8 \mathrm{H}_{2} \mathrm{O}, \\
& \mathrm{C}_{7} \mathrm{H}_{8}+9 \mathrm{O}_{2} \rightarrow 7 \mathrm{CO}_{2}+4 \mathrm{H}_{2} \mathrm{O} .
\end{aligned}
$$

The reaction rates are presumed to be given by Eq. 2. For convenience, a quantity $G$ is defined as

$$
\begin{aligned}
& G^{-1}=\frac{1}{\Delta_{1} \eta_{\mathrm{r}}^{2}} \frac{F_{2} \nu_{\mathrm{F}} Y_{\mathrm{O}_{2}, 2} Y_{\mathrm{F}, 1} q_{\mathrm{F}} p \hat{W}}{C_{2}^{L_{\mathrm{f}}} W_{\mathrm{O}_{2}} R^{0} c_{\mathrm{p}} a_{2,1} L_{\mathrm{F}}^{0.5} T_{2,1}\left(T_{2,1}-T_{1}\right)} \\
& \cdot\left(\frac{\eta_{\mathrm{r}} \sqrt{2 \pi}}{\beta}\right)^{L_{\mathrm{y}}-1}
\end{aligned}
$$

The value of $\beta$ in Eq. 27 is evaluated using Eq. 13 with $T_{2}$ replaced by $T_{2,1}$ and $\eta_{\mathrm{r}}$ is evaluated using Eq. 18. The equation

$\ln G=\ln B-E /\left(R^{0} T_{2,1}\right)$,

obtained from Eqs. 23, 25, and 27 applies at ignition. The overall chemical-kinetic parameters can be obtained from an "Arrhenius" plot of $\ln G$ as a linear function of $1 / T_{2, \mathrm{r}}$. To obtain the "Arrhenius" plot, the quantity $G$ is evaluated using the values for $a_{2,1}$ and $T_{2,1}$ shown in Fig. 6. The slope of this line, obtained by linear least-square fit, gives the activation energy and the frequency factor can be obtained from the equation of this line.

For $n$-heptane and toluene it is assumed that $L_{\mathrm{F}}=2[18]$. For this value of $L_{\mathrm{F}}$, the reduced Damköhler number at ignition is $\Delta_{1}=0.5$ [1]. For $n$-decane and JP-10 it is assumed that $L_{\mathrm{F}}=$ 2.5 [18]. For this value of $L_{\mathrm{F}}$, the reduced Damköhler number at ignition is $\Delta_{1}=0.37$ [1]. The values of $C_{2}$ and $F_{2}$ are obtained from Figs. 3 and 4 respectively. The universal gas constant $R^{0}=8.314 \mathrm{~J} /(\mathrm{mol} \cdot \mathrm{K})$, the average molecular weight $\hat{W}=0.02884 \mathrm{~kg} / \mathrm{mol}$, and the heat capacity $c_{\mathrm{p}}=1150 \mathrm{~J} /(\mathrm{kg} \cdot \mathrm{K})$. The heat release per unit mass of fuel consumed, $q_{\mathrm{F}}$, for $n$ - 


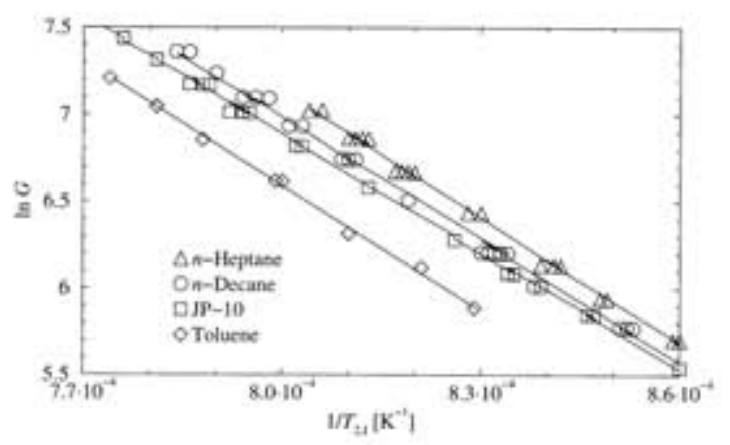

Fig. 7. "Arrhenius" plot of In $G$ defined in Eq. 27 as a function of the reciprocal of the oxidizer stream temperature at ignition, $T_{2 \mathrm{i}}^{-1}$.

heptane, $n$-decane, JP- 10 , and toluene is $4.49 \times$ $10^{7} \mathrm{~J} / \mathrm{kg}, 4.46 \times 10^{7} \mathrm{~J} / \mathrm{kg}, 4.27 \times 10^{7} \mathrm{~J} / \mathrm{kg}$, and $4.09 \times 10^{7} \mathrm{~J} / \mathrm{kg}$ respectively. Figure 7 shows an "Arrhenius" plot of $\ln G$ as a function of $T_{2,1}^{-1}$. Values of $E$ and $B$ deduced from this plot are shown in Table 2.

To test the accuracy of the asymptotic model, overall chemical-kinetic rate parameters are deduced from numerical calculations of the reactive flow-field performed using a computer program developed at RWTH Aachen [20]. The conservation equations of mass, momentum, and energy and the species balance equations used in the formulation of the numerical problem are summarized elsewhere $[20,21]$. Calculations are performed using this computer program over a computational domain of $12 \mathrm{~mm}$. At the boundaries of the computational domain, the mass fractions of the reactants $\left(Y_{\mathrm{F}, 1}\right.$ and $\left.Y_{\mathrm{O}, 2}\right)$, the temperature of the reactants $\left(T_{1}\right.$ and $T_{2}$ ), and the normal components of the flow velocity $\left(V_{1}\right.$ and $\left.V_{2}\right)$ are specified. The values of the tangential component of the flow velocity at the boundaries are set equal to zero. The characteristic strain rate at the stagnation plane is calculated using Eq. 26. Calculations are performed with the chemical reaction between the fuel and oxygen represented by a one-step, irreversible process with the reaction rate given by $\mathrm{Eq} .2$. The values of $B$ and $E$ are so chosen that $a_{2,1}$ and $T_{2,1}$ calculated using these values agree with the experimental data shown in Fig. 6. The numerically calculated values of $B$ and $E$ are given in Table 2. The lines in Fig. 6 represent results of numerical calculations performed using these rates.

The asymptotic analysis and numerical results show that the value of $E$ for $n$-heptane is the highest followed by toluene, $n$-decane, and JP10. For all fuels, the values of $E$ obtained from the asymptotic analysis are smaller than the numerical results. This is attributed to inaccuracies arising from the various assumptions introduced in the asymptotic analysis. In general, the rate constants evaluated using the values of $B$ and $E$ given by the asymptotic analysis are roughly three times greater than those calculated using the values of the overall rate parameters obtained from numerical calculations. If the changes in density in the mixing layer are neglected, then $C_{2}=F_{2}=1.0$. The overall parameters for $n$-heptane for constant density are $E=202 \mathrm{~kJ} / \mathrm{mol}$ and $B=4.06 \times 10^{17}$ $\mathrm{cm}^{3} /(\mathrm{mol} \cdot \mathrm{s})$. For $n$-heptane if $L_{\mathrm{F}}$ is increased from 2 to 3 , the value of $E$ decreases by $2 \%$ and the value of $B$ increases by $15 \%$. The changes in $E$ and $B$ are very small if $\mathrm{Pr}$ is increased from 0.7 to 0.9 .

Experimental data for ignition of hydrogen [12], methane [13], ethane, propane, and butane [14] under nonpremixed conditions have been reported. The temperatures of the oxidizer streams at ignition were measured for various values of the strain rate, mass fraction of fuel in

TABLE 2

Frequency Factor $B$ and Activation Energy $E$ for One-step, Irreversible Reaction Obtained from Interpretation of Experimental Data Using Asymptotic Analysis and from Numerical Calculations

\begin{tabular}{llcccr}
\hline Rate Parameters & & $n$-Heptane & $n$-Decane & JP-10 & Toluene \\
\hline Asympotic & $B\left[\mathrm{~cm}^{3} /(\mathrm{mol} \cdot \mathrm{s})\right]$ & $3.0 \times 10^{17}$ & $1.5 \times 10^{17}$ & $6.3 \times 10^{16}$ & $1.5 \times 10^{17}$ \\
analysis & $E[\mathrm{~kJ} / \mathrm{mol}]$ & 200.7 & 195.0 & 186.9 & 199.2 \\
Numerical & $B\left[\mathrm{~cm}^{3} /(\mathrm{mol} \cdot \mathrm{s})\right]$ & $5.9 \times 10^{17}$ & $1.8 \times 10^{17}$ & $8.6 \times 10^{16}$ & $2.4 \times 10^{17}$ \\
calculations & $E\left[\mathrm{~kJ} / \mathrm{mol}^{17}\right.$ & 218.0 & 208.5 & 202.5 & 217.0 \\
\hline
\end{tabular}


the fuel stream, and pressure [12-14]. Direct comparisons of the temperatures of the oxidizer streams at ignition for these different fuels with those in Fig. 6 are not possible because the conditions are not the same. At fixed strain rate the temperature of the oxidizer stream at ignition decreases with increasing concentrations of fuel in the fuel stream and with increasing pressure [12-14]. The temperatures of the oxidizer streams at ignition for methane are the highest and those for hydrogen are the lowest.

In previous studies overall chemical-kinetic rate parameters have been deduced from extinction data of nonpremixed $n$-heptane flames obtained in the counterflow configuration $[7,8$, $10,11]$. The overall rate parameters for $n$ heptane reported in Ref. 11 are $E=110 \mathrm{~kJ} / \mathrm{mol}$ and $B=2.8 \times 10^{13} \mathrm{~cm}^{3} /(\mathrm{mol} \cdot \mathrm{s})$. They are different from those given in Table 2 . This illustrates that the overall chemistry taking place in the flame at conditions close to extinction are different from those close to ignition. The maximum temperatures in the reactive flow-field at conditions close to extinction are between $1400 \mathrm{~K}$ and $1700 \mathrm{~K}$ and those close to ignition are between $1125 \mathrm{~K}$ and $1250 \mathrm{~K}$. At the higher temperatures the concentrations of radicals are higher. Hence close to extinction, reactions in which radicals participate become more important. The activation energies of these reactions are generally small. For ignition to take place radicals must be produced. The activation energies of these reactions are generally high.

\section{CONCLUDING REMARKS}

The asymptotic analysis clearly illustrates the influence of various parameters on ignition as shown in Eqs. 23 and 25. The overall chemicalkinetic parameters deduced here can be employed in numerical calculations where simplified description of the chemistry is desired. The experimental data shown here can be used to test predictions of detailed chemical-kinetic mechanisms. Experimental data on ignition of gaseous fuels such as hydrogen [12] and methane [13] in counterflow configuration have been used previously to test predictions of detailed [22], skeletal, and reduced chemistry [23]. The asymptotic analysis developed here is expected to be useful in future rate-ratio asymptotic analysis of ignition using reduced chemistry.

The authors thank Professor P. A. Libby and Professor F. A. Williams for helpful discussions. The research conducted at the University of California at San Diego was supported by the U.S. Army Research Office through Grant DAAD1999-1-0259, under the direction of Dr. David M. Mann. The research at Universidad Politécnica de Madrid was supported by contract from INTAUPM Mezcla y Combustion.

\section{REFERENCES}

1. Liñán, A., and Williams, F. A., Combust. Flame 95: 31-46 (1993)

2. Fendell, F. E., J. Fluid Mech. 21:281-303 (1965).

3. Liñán, A., Acta Astronautica 1:1007-1039 (1974).

4. Law, C. K., Combust. Flame 24:89-98 (1975).

5. Liñán, A., and Crespo, A., Combust. Sci. Technol. 14:95-117 (1976).

6. Niioka, T., Eighteenth Symposium (Intemational) on Combustion, The Combustion Institute, Pittsburgh, 1981, pp. 1807-1813.

7. Seshadri, K., and Williams, F. A., in Halogenated Fire Suppressants, Vol. 16, (R. G. Gann, Ed.), American Chemical Society, Washington, DC, 1975, pp. 149182.

8. Hamins, A., and Seshadri, K., Combust. Sci. Technol. 38:89-103 (1984).

9. Puri, I. K., and Seshadri, K., Combust. Flame 65:137150 (1986).

10. Trees, D., Seshadri, K., and Hamins, A., in Halon Replacements: Technology and Science, (A. W. Miziolek and W. Tsang, Eds.), Vol. 611 of ACS Symposium Series, American Chemical Society, Washington, DC, 1995, pp. 190-203.

11. Seiser, R., Truett, L., Trees, D., and Seshadri, K. Twenty-Seventh Symposium (International) on Combustion, The Combustion Institute, Pittsburgh, 1998, pp. 649-657.

12. Fotache, C. G., Kreutz, T. G., Zhu, D. L., and Law, C. K., Combust. Sci. Technol. 109:373-393 (1995).

13. Fotache, C. G., Kreutz, T. G., and Law, C. K., Combust. Flame 108:442-470 (1997).

14. Fotache, C. G., Wang, H., and Law, C. K., Combust. Flame 117:777-794 (1999).

15. Krishnamurthy, L., Williams, F. A., and Seshadri, K., Combust. Flame 26:363-377 (1976).

16. Seshadri, K., and Williams, F. A., Int. J. Heat Mass Transfer 21:251-253 (1978).

17. Williams, F. A., Hanson, R. K., and Segal, C., 1999 JANNAF Combustion, Propulsion Systems Hazards, Air Breathing Propulsion Subcommittee, Joint Meetings, 1999. 
18. Seiser, R., (2000). Ph.D. thesis, Technical University of Graz.

19. Weißweiler, T. (1994). Diploma thesis, Institut für Allgemeine Mechanik, RWTH Aachen, Aachen, Germany.

20. Pitsch, H. (1993). Master's thesis, RWTH Aachen, Germany.

21. Peters, N., in Reduced Kinetic Mechanisms for Applications in Combustion Systems, (N. Peters and B. Rogg,
Eds.) Vol. m15 of Lecture Notes in Physics, SpringerVerlag, Heidelberg, 1993, pp. 1-13.

22. Sung, C. J., and Law, C. K., Combust. Sci. Technol. 129:347-370 (1997).

23. Kreutz, T. G., and Law, C. K., Combust. Flame 114: 436-456 (1998).

Received 19 October 1999; revised 13 March 2000; accepted 14 March 2000 